Garrod, Practitioner, vol. 1xxii, p. 395, March, 1904. 7 Von Noorden. Autointoxication, p. 43.8 Ibid., p. 37.9 Dreschfeld and Moore. Med. Chrom. May, r904. '10 Edsall, Philadel. Med. Journ., 1902, vol. i, p. ris5. il Edsali.' Amer. Journ. of Med. Sci., Vol. exx , p. 629, April, 1902. 12 Hale White, pare, however, Beddard, Pembry, and Spriggs, Lancet, ${ }_{1903}$, vol i, May r6th.

\section{THE INCUBATION PERIOD OF PNEUMONIA.}

\section{By EUSTACE M. CALLENDER, M.D.BRUX., L.R.C.P.LOND., M.R.C.S.ENG.}

ALthoбar the pneumococcus (Fraenkel) does not conform to Koch's postulates, there is, I take it, little or no doubt in the minds of most physicians that it is the specific micro-organism of acute pneumonia. The same micro-organism is almost constantly found in the mouth, but seldom, if ever, in the nasal passages and cavities in health. In acute inflammatory affections of these passages and cavities it is, I believe; very generally present; in fact, it is probably the cause of many of these inflammations as well as of at least some cases of acute otitis media.

Several endeavours have been made to fix a more or less definite period of incubation in pneumococcus infections, and most writers appear to agree in believing such periods to be short. Mr. T. B. Franklin Eminson says : "It is the general opinion that the incubation period is very short-a few hours to a few days." Dr. Parsons says: "The length of the period of incubation is doubtiul, but it appears to be short, from a few hours to two days."

The difficulty in fixing a definite incubation period in any disease must alwags be due in great measure to the difficulty in ascertaining the actual source of infection and the time of exposure. In the Lyon Médical, April 28th, 1889, is published an exceedingly instructive series of three cases in which the source of infection could be accurately ascertained and a definite time of exposure to infection ascertained. In these cases the incubation period was almost accurately forty. eight hours.

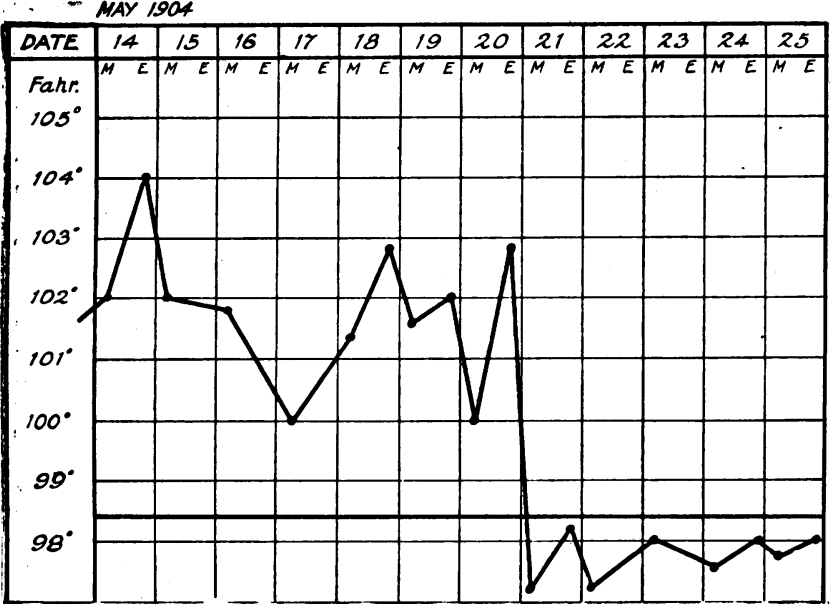

I venture to think that the series of cases now published is even more striking and instructive.

$$
\text { CASE I. }
$$

P. M female, aged is years, living at home with her parents, showed definite symptoms of a severe nasopharyngitis on the evening of May 8 th, rgo4. When first seen on May $r$ th her left antrum was full of muco-purulent secretion, and there was a profuse nasal discharge. Temperature was $\mathrm{IO}_{2} \mathrm{O} F$., and there was a very marked prostration.

\section{CASE II.}

C. M., male, aged 49, father of Case I, was in good health on the evening of May roth, but had a severe headache on rising the next morning (May Irth). He went as usual to his office in the morning, but returned home at I p.m., too ill io work. I saw him some two hours later. He had a typical left basal pneumonia. His illness was of the most severe type, and he died of toxaemia on the eighth day of the disease.

Case III

Mr. B. had two conversations with the last patient (Case II) on the morning of May $1 \mathrm{rth}$, one in his private office, and one in another part of the same building. He was well on rising on May isth, but had a sharp rigor during breakfast, and vomited two or three times during that morning. His illness was of a somewhat indefinite character, and ended favourably with a very definite crisis on May. 2 rst, the eighth day of illness.
CASE IV.

M. S., aged 28, female, domestic servant. This patient was for a short time on the mornings of May r2th and isth in the sick-room of Case II. On the morning of the $x$ th she was too ill to work, and I was asked to see her. She was flushed and obviously ill. She complained of "sore throat" and very considerable dysphagia. Temperature was 102 $\circ \mathrm{F}$. There was marked prostration and very obstinate constipation. The fauces and pharynx were to the naked eye normal, but the patient complained of constant discomfort in the throat, which amounted to pain on deglutition. Pain was most severe on swallowing saliva, rather less on drinking, and least of all when swallowing solids. The reasons for detailing these symptoms will appear later. This patient's illness was not severe. She was ill for a week, becoming rapidly better during the seventh day. Her temperature was easily kept in check with quinine and diaphoretics.

CASE v.

Mrs. W., aged 63 , a relative of Mr. C. M. (Case II), was in the house during the whole of this latter patient's illness, but never entered the sick-room until the early morning of May 17 th ( 1 a.m.). Having helped the nurses in their duties for a few minutes, she lay down on a couch at the foct of the sick bed, and fell asleep. She remained thus for about cne hour, and then left the room. On May roth she left London by a morning train, was taken ill in the train, and reached home in Worcestershire with a temperature of $103^{\circ} \mathrm{F}$. She died of acute pneumonia on the morning of May 22 nd.

Now granting that all these were cases of pneumococcus infection, they form, I think, a very instructive and remarkable series, and show a very fairly regular length of incubation period.

Of the nature of the disease in Cases II and $\nabla$ there can be no doubt. Case II was seen in consultation on two occasions by Dr. James Galloway. It was a typical case of virulent pneumonia. Case V I did not personally see, but there can be no doubt of the nature of her fatal illness. No one is likely to question her having become infected, in all proba: bility, between I and 2 a.m. on May I th by Case No. II.

Of the three remaining cases-I, III, and IV-can they be claimed as cases of pneumococcus infection? I believe that they can. With regard to Case I, I had a precisely similar illness myself in December, 1903. It commenced with marked prostration, obstinate constipation, and considerable dysphagia. The dysphagia exactly corresponded with that present in Case IV, and I was struck at the time with the fact that the fauces and pharynx appeared to be absolutely normal. After a few days there was a profuse muco-purulent nasal discharge, accompanied by very severe supraorbital and infraorbital neuralgia. I consulted my friend, $\mathbf{M r}$. Ernest $B$. Waggett, who found the left antrum full of muco pus.

Examined bacteriologically by Mr. G. Leslie Easteg, this muco-pus was found loaded with pneumococci. I now much regret that a similar examination was not made in Case $r$, but naturally I had no idea of the developments which were to follow. Still I do not hesitate looking at all the facts, to attribute to this case the production of the others of the series. Was Case III a case of pneumococcus infection? I did not see this patient myself, but I have been favoured by his medical adviser, Dr. James Brown, of Tring, with the following account of the case :

Mr. B. got up feeling quite well on May 14 th, but had a sharp rigor during breakfast, and was sick two or three times. He was seen in the course of the morning, his temperature being ro2 ${ }^{\circ}$, and his respirations rather hurried. He made no complaint of pain, but said he felt a little stiff over the right side of the back below the scapula. The bread sounds in that situation were rather feeble, but there was no dullness on percussion, and no abnormal sounds either there or over the rest of the chest. He did not look very ill, was not flushed, had a slight cough, bronchial in character, but no expectoration either then or at any time during his illness. I have not been able te give you a record of his respirations, as Mrs. B. unfortunately destrosed the chart ..... but it varied from 20 to 48 , and never gave him any distress except when he was moved. On May I8th I thought I could detect a few very fine crepitations on the left side of the back at the angle of the scapula, and on May 20 th there were a few on the same side in front about $2 \frac{1}{2}$ in . below the nipple, but they were not very marked in either s:tuation. Ho had a marked crisis on May 2 Ist, and has gone on well since, but there have been no sounds in his chest, and practically no cough. He has a slight rheumatic tendency, with a permanent sy stolic murmur. At the beginning of the attack this became much more marked and rougher in character, but it quieted down again about the fourth day.

The onset, the indefinite pulmonary signs, the very marked increase of frequency of respiration, the definite crisis at the end of the seventh day or the beginning of the eighth, I think more than suggest a pneumococcus infection, especially when we remember his two interviews with Case II on May IIth, who was then suffering from pneumncoccus infection of a most virulent t.ype. There only remains Case IV. a very indefinite case undoubtedly. Her symptoms, however, so exactly resembled those I suffered from myself, and 
which were subsequently proved to be due to pneumococcus infection, that I do not hesitate to add the case to the others of the series. The patient was a strong, healthy woman. She was seen almost immediately after the development of her first symptoms, and vigorous treatment was commenced at once. No development of further symptoms occurred, but there was definite illness and prostration, which lasted until the seventh day.

In conclusion, it is interesting to note the length of the incubation period in each case. Of the source of infection in Case I we know nothing. She could not have infected Case II as far as we know, before the night of May 8 th. He recognized his first symptoms on rising on May I th-roughly, say, fiftyeight hours. Case II and Case III were in contact for a short time between 10 a.m. and I p.m. on May I Ith. The first symptoms were exhibited during breakfast on May 14throughly, sixty-nine hours. The earliest period of infection of Case IV appears to have been about Io a.m. on May 12th, and her first symptoms appeared at 7 a.m. on the 14 th-a period of only forty-five hours. This period is, however, open to question, as this patient had already run a distinct risk of infection by washing the infected handkerchiefs used by Case I.

Case $\nabla$ appears to be much more definite as regards incubation. I saw the patient constantly whilst visiting Cases I and II; she was in vigorous, good health. One one occasion, and one only, was she in the sick-room for anything more than a minute or two; we may, I think, reasonably take it that she became infected between 1 and 2 a.m. on May 17 th She began to feel ill about 9 a.m. on May Igth-a period of fifty-five hours.

Epidemic Pneumonia at Scotter, by T. B. Franklin Eminson (H. Kimpton London, 1902). Twentieth Annual Report of the Local Government Board, 890-1, pp. 95 et seq. of the Supplement.

\section{Kemarks}

ON

\section{Chronic Gastric ULCER AND PyLORIC STENOSIS}

AND THEIR TREATMENT BY GASTRO-ENTEROSTOMY.

Read before the Croydon Division (South-Eastern Branch) of the British Medical Association.

By HERBERT F. WATERHOUSE, M.D.EDIN., F.R.C.S.ENG.,

surgeon, Charing Cross Hospital.

Gantlemen,--When your President, Dr. Duncan, did me the honour of inviting me to address you this afternoon he asked me for a paper on some subject of practical importance. I had little hesitation in selecting as my subject "Gastroenterostomy in Non-malignant Affections of the Stomach," and this for two reasons. First, because I am convinced that gastric disorders form a no inconsiderable proportion of the cases you are called upon to treat in your daily practice and, secondly, because this operation has, during the past three years especially, afforded me results so gratifying and so far exceeding my most sanguine anticipations in the treatment of these chronic, painful, and too frequently mortal diseases that I am glad of this opportunity of trying to infect you with some fraction of my enthusiasm for this, in such disorders, almost ideal operation.

The time at my disposal is, however, so short that I can only refer to gastro-enterostomy in two of the many nonmalignant gastric disorders, and I naturally choose those of which I have had the largest experience-namely (I) simple ulcer of the stomach, and (2) stenosis of the pylorus, with or without chronic gastric dilatation. Before proceeding to the special consideration of these two disorders I will bring under your notice briefly a few general statements.

In almost all lesions of the stomach there is present a certain degree of dyspepsia. And here let me enter my protest against the far too common practice of treating dyspepsia as if it were a definite disease. It is merely a symptom as of to a multitude of gastric disorders. So far as I, as a surgeon, am concerned, when brought face to face with a patient who complains of dyspepsia, I ask myself this question: Is the dyspepsia due (I) to abnormal gastric secretion, or (2) to interference with the movements of the stomach, especially those which are concerned with the transmission of the food from the stomach into the duodenum through the pylorus, or (3) to these factors combined?

It is to be borne in mind that the function of the musculature of the non-pyloric part of the stomach is to move the gastric contents about so as to ensure their complete admixture with the gastric juice and not to transmit food from stomach into duodenum, this act being the function of the pyloric segment. Hence anything which mechanically hinders the contraction of the musculature of the pyloric segment tends to prevent the normal evacuation of the stomach contents into the duodenum; this also explains the fact that in the great majority of cases of pyloric stenosis the compensatory hypertrophy is limited to the pyloric segment of the stomach, a statement $I$ have frequently verified in vivo.

Of the chemistry of the stomach I hardly dare to speak, as it is a subject upon which my knowledge is exceedingly small. I will content myself, therefore, with a few statements. The normal acidity of the gastric juice is due to free hydrochloric acid which is present to the extent of 0.18 per cent. It is this mineral acid which is the great microbe-destroyer and antiseptic of the stomach. When it is absent fermentative changes occur in the stomach occasioned by bacteria introduced with the food and give rise to the organic acids of decomposition, lactic, butyric and acetic. When $\mathrm{HCl}$ is present in excess, hyperchlorhydria exists-a condition frequently found in association with gastric ulcer. It is, of course, well known that free $\mathrm{HCl}$ is commonly absent in cases of carcinoma of the stomach. I have learned not to rely upon its absence as a sign of carcinoma unless three different examinations of the gastric contents after three test meals agree in proving that it is not present. A single examination has mised me more than once.

In the vomit in my cases of gastric dilatation secondary to non-malignant pyloric stenosis sarcinae ventriculi have always been found and yeast fungi have very frequently been present.

It may be mentioned as a matter of prime importance that seven and a-half hours after a moderate meal the normal stomach is quite empty of food and that the reaction of its mucus is neutral or nearly so. Should particles of food be present, especially in any amount, it may be assumed that the motor power of the stomach is seriously impaired. If in the morning I find that washing out of the stomach reveals the presence of distinct food particles taken at dinner the preceding evening, say twelve to thirteen hours previously, I conclude that I have to deal with pploric stenosis. I do.not deny that there may be some cases of atony of the stomach apart from pyloric obstruction, but I can definitely state that I as a surgeon have never met with such, and that reliance on this sign has enabled me, in many cases, to form a correct diagnosis whilst it has never misled me.

\section{Chronic Gastric Ulcer.}

Though I am attempting to place before you the surgical teatment of gastric ulcer and of pyloric stenosis, no hard-andfast line can be drawn between these two lesions, as in many cases the stenosis of the pylorus is not organic but spasmodic, and due to the presence of an ulcer, fissure, or erosion in the pyloric segment of the stomach, which may be of considerable gize or so minute as to escape notice on hasty examination. Pyloro-spasm has been frequently present in my series of cases and I have had two opportunities of observing in very emaciated patients that though the pylorus could be distinctly felt through the abdominal walls as a small hard tumour prior to the administration of the anaesthetic, this tumour became less palpable as the anaesthesia was in progress, disappeared entirely under complete anaesthesia, commenced to reappear after suspension of the administration, owing to respiratory embarrassment necessitating artificial respiration which allowed the patient nearly to come out of the anaesthesia, and disappeared again on the re-establishment of deep anaesthesia. I am as convinced of the existence of pyloro-spasm due to pyloric ulcer as I am of anal spasm caused by anal ulcer and fissure. From my experience I would consider pyloro-spasm almost as frequent a cause of pyloric stenosis as cicatricial contraction. In other words, I hold that, so far as non-malignant ulcers are concerned, an open ulcer is almost as frequent a cause of narrowing, spasmodic, I admit, but none the less real in its effect, as is a cicatrized ulcer.

The great indication for gastro-enterostomy in simple ulcer of the stomach is the occurrence of repeated haemorrhages. I have never operated for a first haemorrhage from the 